\title{
A METHOD FOR CRACK WIDTH EVALUATION OF CONTINUOUS COMPOSITE GIRDER BRIDGES ACCOUNTING FOR SHEAR-LAG EFFECT
}

\author{
Qaiser-uz-Zaman KHAN ${ }^{1}$, Takuji HONDA ${ }^{2}$, Yoshiaki OKUI ${ }^{3}$ and Masatsugu NAGAI ${ }^{4}$ \\ ${ }^{1}$ M. Eng., Graduate Student, Dept. of Civil \& Environmental Eng., Saitama University \\ ${ }^{2}$ Student member of JSCE, Graduate Student, Dept. of Civil \& Environmental Eng., Saitama University \\ ${ }^{3}$ Member of JSCE, Dr. Eng., Associate Professor, Dept. of Civil \& Environmental Eng., Saitama University \\ (255, Shimo-Okubo, Saitama, 338-8570, Japan) \\ ${ }^{4}$ Member of JSCE, Dr. Eng., Professor, Dept. of Civil \& Environmental Eng., Nagaoka University of Technology \\ (1603-1, Kami-Tomioka, Nagaoka, Niigata, 940-2188, Japan)
}

\begin{abstract}
A numerical procedure for crack width evaluation of steel-concrete composite girder bridges under negative bending moment is proposed. The procedure is combination of 3-dimensional finite element (FE) analysis with smeared crack model and a bond-slip differential equation. From the FE analysis, the averaged behaviour including shear-lag as well as cracking is calculated. Then, the crack width is evaluated by using the differential equation and the FE results. Attention is paid to the consistency between the FE modelling and the employed bond-slip differential equation. The obtained crack widths are shown to compare well with those from experiments on composite girder specimens.
\end{abstract}

Key Words: continuous composite bridge, crack width control, effective width, smeared crack model, shear lag

\section{INTRODUCTION}

In steel-concrete continuous composite girder bridges, negative bending moments produce tensile forces in concrete slabs near intermediate supports. These tensile forces can cause cracking of the concrete slabs even under service loads. Since cracking of the concrete slab allows penetration of water thereby advancing corrosion of reinforcement, some measures are needed to ensure the durability of composite bridges under service loads. There are two methods to deal with cracking in design practice, firstly preventing cracks, and secondly allowing formation of cracks but keeping their crack widths within an allowable limit. If crack prevention method is adopted, prestressing by jack up/down of supports or installation of prestress cables has to be used. However, the design method allowing crack formation without prestressing is preferable in practice because of economy and simplicity at a construction stage.

In compliance with this demand, a crack-control procedure for composite girders has been specified in a draft Eurocode $4^{1)}$ since 1996. This procedure is based on Hanswille's theory ${ }^{2}$, in which a bond-slip differential equation for RC members is utilized for deriving a relationship between the crack width and the stress in a RC slab, and the beam theory is employed to evaluate the stress from the applied bending moment. Japanese crack-control procedures ${ }^{3), 4)}$ are the essentially same as Hanswille's theory except for employing the empirical relationship between the crack width and the stress specified in Japanese standard specifications for concrete structures ${ }^{5)}$ instead of that derived from the bond-slip differential equation in Hanswille's theory. In both crack control procedures, the effective width concept is utilized to take account of the shear-lag effect. The design formulae for effective width, however, are not originally intended to account for the shearlag effect on the crack width, In particular, for the Japanese crack-control procedure, the used effective-width formula prescribed in Japanese Specifications for Highway Bridges ${ }^{6}$ (JSHB) is intended to evaluate the maximum stress at a flange-web juncture assuming elastic behaviour without cracking. 
Hence, there is some doubt about applicability of the effective width formula in JSHB to crack width evaluation.

In this paper, first we investigate the applicability of JSHB's effective width formula based on the experimental data reported by Shito et al. ${ }^{7}$. To this end, a composite girder specimen with a wide concrete slab is needed, and their experiment accords with this requirement.

Next, in order to propose a design formula for effective width of a flange, it is necessary to develop a numerical method for crack width evaluation, because the proposal of such a design formula requires many parametric studies. In most conventional stud$i^{8)-12)}$ on shear-lag behaviour, linear elastic material properties are assumed, and only few attempts ${ }^{13)}$ have so far been made at taking account of nonlinear behaviour due to cracking of concrete slab in a hogging bending region. Furthermore, the objective of this nonlinear shear-lag analysis ${ }^{13)}$ is to evaluate an effective width for ultimate load-carrying capacity and not for crack width in a concrete slab.

In this paper, hence, we propose a numerical procedure for crack width evaluation, in which the shear-lag effects can be taken into account. In chapter 4 , the proposed procedure is verified through comparison with experimental data ${ }^{14)}$. Although this paper addresses only proposal and verification of a numerical procedure for crack width evaluation, the proposed procedure can be utilized in future parametric studies to propose an effective width formula for the crack width problem.

\section{APPLICABILITY OF EFFECTIVE WIDTH FORMULA TO CRACK WIDTH EVALUATION}

In this chapter, we investigate applicability of the effective width formula specified in JSHB to crack width evaluation through comparison with experimental data. To this end, first an experiment conducted by Japan Highway Public Co. (JH) is introduced briefly in the next section. Then, the crack widths according to Japanese design recommendations ${ }^{5), 6)}$ with the effective width formula are compared with the experimental data to verify the applicability.

\section{(1) Experiment by Japan Highway Public Co.}

Shito et al. ${ }^{7)}$ conducted a loading test of a fullscale part of a composite 2-I girder bridge recently constructed in Japan ${ }^{15}$. The half of the cross section, and load and support conditions of the specimen are shown in Fig.1(a) and (b), respectively. The specimen was loaded to reproduce a stress state near an intermediate support at a service load level of $P=1590 \mathrm{kN}$.

Transverse crack widths were monitored with $\pi$ gauges glued on the top surface of the concrete slab. Since the $\pi$ gauges were installed only near steel Igirder positions(see Fig.1), transverse crack widths only over the steel I-girders were measured, and no transverse crack widths in the central part of the concrete slab were reported. However, the reported crack pattern on the top of the concrete slab showed that transverse cracking localized into a region of the concrete slab over the steel I-girders, and that few cracks propagated into the central part of the concrete slab. This suggests that inelastic strain due to cracking near the I-girder is larger than in that in the central concrete slab, and accordingly that shearlag behaviour takes place in wide concrete slabs in recent 2 I-girder bridges. In the next subsection, we will investigate applicability of the effective width formula specified in JSHB by comparing these experimental data.

\section{(2) Crack width evaluation with effective width}

JH's design manual ${ }^{3)}$ recommends to evaluate the crack width $w$ according to the following expression:

$$
\left.w=k\left\{4 c+0.7\left(c_{s}-\phi\right)\right)\right\}\left(\frac{\sigma_{s e}}{E_{s}}+\varepsilon_{c s d}\right)
$$

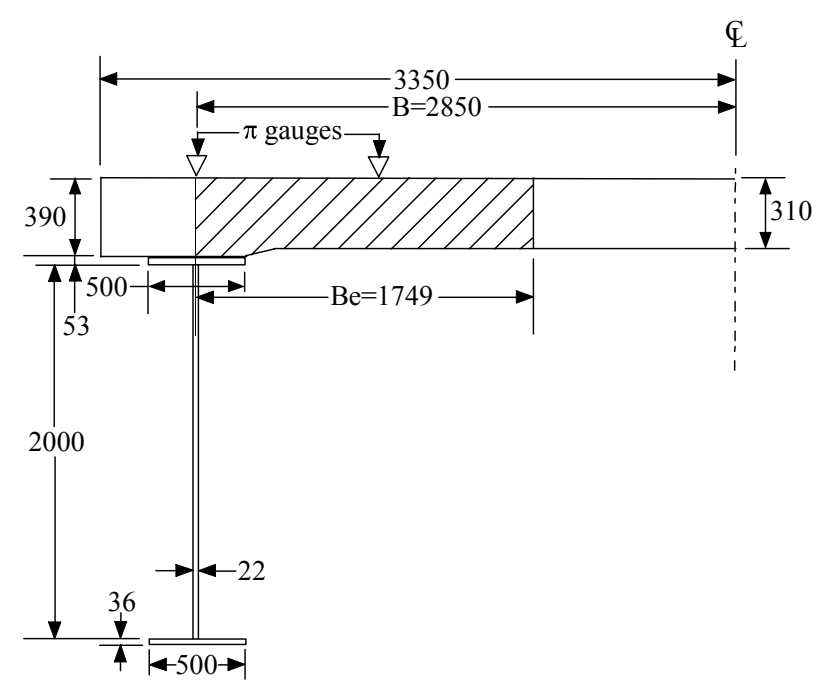

(a) Half cross section

\section{$\mathrm{G}$}

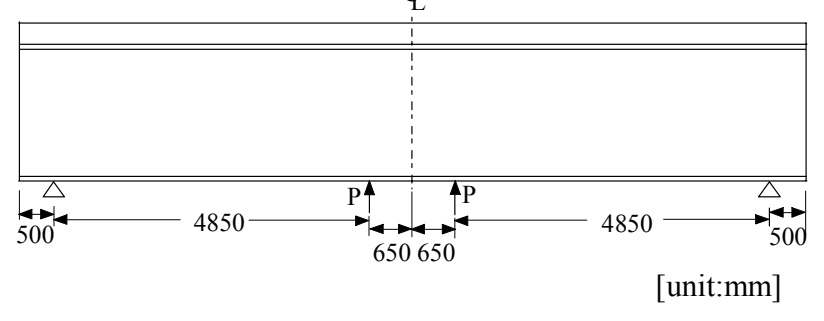

(b) Side view

Fig.1 Test specimen by $\mathrm{JH}^{7)}$. 
where $\sigma_{s e}$ is the stress increment of reinforcement bar and is given

$$
\sigma_{s e}=\sigma_{s}-\beta f_{c t}\left\{\frac{1}{\rho}-\frac{1}{\rho \alpha_{s t}}\right\}
$$

where $k=1.0$ for deformed bar; $c=$ concrete cover of reinforcement; $c_{s}=$ reinforcement spacing; $\phi=$ diameter of reinforcement; $E_{s}=$ Young's modulus of steel; $\varepsilon_{c s d}=$ concrete strain due to creep and shrinkage; $\sigma_{s}=$ steel stress in state II, in which only steel girder and reinforcement are considered;(see Fig.3a) $\beta=0.2$ : coefficient for tension stiffening; $f_{c t}=$ tensile strength of concrete; $\rho=A_{s} / A_{c}$ : reinforcement ratio; $\alpha_{s t}=\left(A_{s t} J_{s t}\right) /\left(A_{a} J_{a}\right) ; A_{s t} J_{s t}=$ area and second moment of area of composite section neglecting concrete $\left(A_{s t}=A_{a}+A_{s}\right) ; A_{a}, J_{a}=$ area and second moment of area of steel girder; $A_{s}=$ area of reinforcement; $A_{c}=$ area of concrete.

When evaluating $\sigma_{s e}$ with Eq.(1b), reinforcing bars within only the effective width of the concrete slab are taken into account. The stress increment $\sigma_{s e}$ and accordingly crack width $w$ hence vary with changing the effective width.

Fig.2 shows the relationship between the nondimensional effective width $B_{e} / B$ and the crack width evaluated from Eq.(1) for the specimen in Fig.1. In the calculation of $w$, we use $\varepsilon_{c s d}=120 \mu, f_{c t}=2.92 \mathrm{MPa}$ from the material test and monitoring results for this specimen ${ }^{7)}$. In addition, the maximum and mean crack widths obtained from the experiment together with the nondimensional effective width evaluated from JSHB are plotted in Fig.2. It can be seen from Fig.2 that the combination of Eq.(1) and the effective width formula in JSHB underestimates the maximum crack width, and that the effective width that gives the maximum crack width is about $47 \%$ smaller than that specified in JSHB. Of course, since this inadequacy in the effective width formula is judged from only one specific experimental result and the scatter of experimental maximum crack width is quite large, we can not conclude the inadequacy immediately. Nevertheless, it seems that the current effective width formula in JSHB should be used for the crack width evaluation with great care.

\section{FE MODELLING AND METHOD OF CRACK WIDTH EVALUATION}

\section{(1) Outline of proposed method}

In the proposed procedure of crack width evaluation, first, 3D finite element analysis of composite girders is employed to evaluate average behaviour of reinforced concrete slabs, which include effects of concrete cracking and the shear-lag. The smeared crack model ${ }^{16)}$ is used in the FE analysis. Then, the crack width is calculated from the average strains by using the bond-slip differential equation used by Hanswille ${ }^{2)}$.

There are two main approaches for modelling concrete cracking in FE analysis, namely discrete crack models and smeared crack models. In the discrete crack approach, cracking is modelled as separation of an interface element between boundaries of elements. The separation occurs when the nodal force which is normal to the element boundaries reaches the tensile strength. It is possible to evaluate crack widths directly, but cracks need to follow the element boundaries. This approach requires introduction of additional nodal points and interface elements between each reinforcement bar and surrounding concrete. Consequently, the numerical implementation of the discrete crack model on large structures is very difficult in practice.

In the smeared crack approach, a cracked solid is considered to be a continuum in which the stressstrain relationships are still valid. After cracking, the initial isotropic stress-strain relation are replaced by an orthotropic stress-strain relation. Thus, the topology of the original finite element mesh is not required to be changed. Computationally, the smeared approach is very efficient and simpler, because only the constitutive relation are needed to be changed in the element region of interest after the appearance of cracks. Since large-scale analyses of real compositegirder bridges are required in the present problem, the smeared crack analysis was used.

\section{(2) FE modeling of reinforced concrete member}

A constant cut-off criterion was used as a cracking criterion in the FE modeling of concrete. In this criterion, when the maximum principal stress attains to the concrete tensile strength, a crack occurs in the

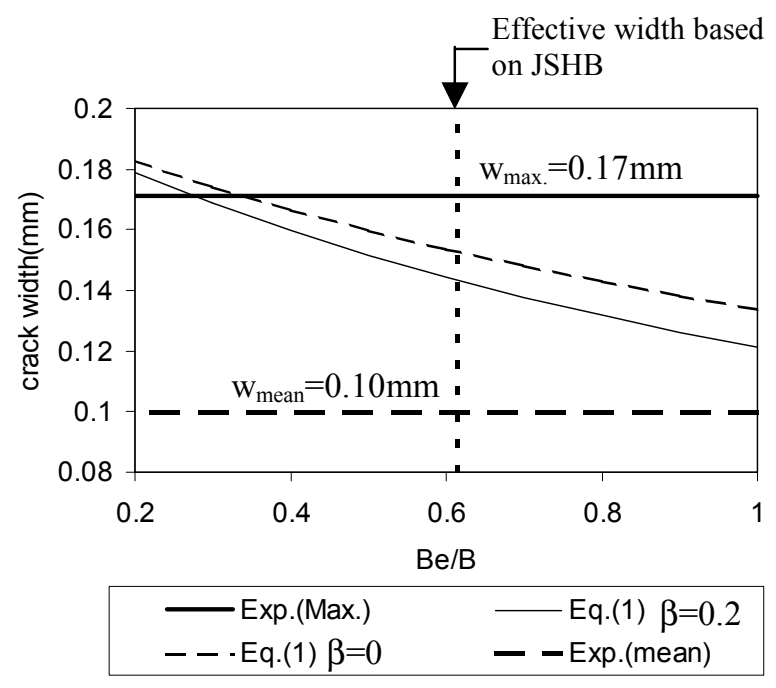

Fig.2 Crack width vs. effective width relationship. $\left(\right.$ Experimental data from Shito et $\mathrm{al}^{7)}$ ) 
direction normal to the maximum principal direction In addition, the fixed crack model was used, because rotation of the principal stress after first cracking is negligible in the considered problem. A constant shear retention relation was used to take account of the reduction in the shear stiffness, due to cracking.

Reinforcement steel bars were modelled as embedded elements. In this element, the bar elements do not have independent degrees of freedom. Instead, the stiffness of the bar elements were superposed on that of mother concrete elements. Although perfect bonding between concrete and embedded reinforcement is assumed in this modelling, bond-slip effect can be taken into account by using an average stress-strain relationship of reinforced concrete including tension stiffening effect.

Fig.3(a) shows a schematic figure of the average stress-strain relation derived from the bond-slip differential equation proposed by Hanswille explained in the next subsection. The state I corresponds to perfect bonding, while the state II to perfect cracking. The average stress $\bar{\sigma}$ of a RC member is expressed in terms of average steel stress $\bar{\sigma}_{s}$ and average concrete stress $\bar{\sigma}_{c}$,

$$
\bar{\sigma}=\frac{1}{V} \int_{V} \sigma d V=\frac{1}{1+\rho}\left(\bar{\sigma}_{c}+\rho \bar{\sigma}_{s}\right)
$$

where for a uniaxial stress state,

$$
\bar{\sigma}_{c}=\frac{1}{L} \int_{0}^{L} \sigma_{c} d V, \quad \bar{\sigma}_{s}=\frac{1}{L} \int_{0}^{L} \sigma_{s} d V
$$

$V=A_{t} L$ is the total volume of the RC member with the cross-sectional area $A_{t}=A_{c}+A_{s}$ and length $L$.

On the other hand, the average concrete strain equals the average steel strain under the assumption of perfect bonding used in the present smeared FE analysis. However, it should be noted that the average concrete strain $\bar{\varepsilon}_{c}$ includes contribution of crack opening in concrete. If we separate the average strain into an intact part and a cracking part, we have

$$
\begin{aligned}
\bar{\varepsilon}_{c} & =\frac{1}{L} \int_{0}^{L} \frac{d u}{d x} d x=\frac{1}{L}\left(\int_{L^{*}} \frac{d u}{d x} d x+\sum[u]\right) \\
& =\varepsilon_{c m}+\sum w / L
\end{aligned}
$$

where $\varepsilon_{c m}$ denotes the average strain over the intact $\operatorname{part} L^{*} ; w=[u] \equiv u^{+}-u^{-}$is the crack width, and the summation is taken over all cracks in $L$.

In summary, since normal stresses are zero in the cracking part, we have

$$
\begin{aligned}
& \bar{\sigma}_{c}=\sigma_{c m}, \quad \bar{\sigma}_{s}=\sigma_{s m,} \\
& \bar{\varepsilon}_{c}=\bar{\varepsilon}_{s}=\varepsilon_{s m}=\varepsilon_{c m}+\Sigma w / L
\end{aligned}
$$

where the overbar denotes averaged quantities over the total region, while the subscript " $m$ " stands for averaged quantities over the intact part. In the present smeared FE analysis, we obtain the averaged quantities over the total region as output.

Since the elastic perfectly plastic model is assumed for stress-strain relation of reinforcement steel as shown in Fig.3(b), the stress-strain relation for concrete can be derived from the average stressstrain relation from Hanswille's theory ${ }^{2)}$ by using Eq. (5). The derived stress-strain relation of concrete is modelled as a multilinear curve in FE analysis.

\section{(3) Crack width evaluation from average stresses}

In this subsection, a procedure for evaluating the crack width from the average stress is explained. In the proposed procedure, we employ the same constitutive equation and differential equation for bond-

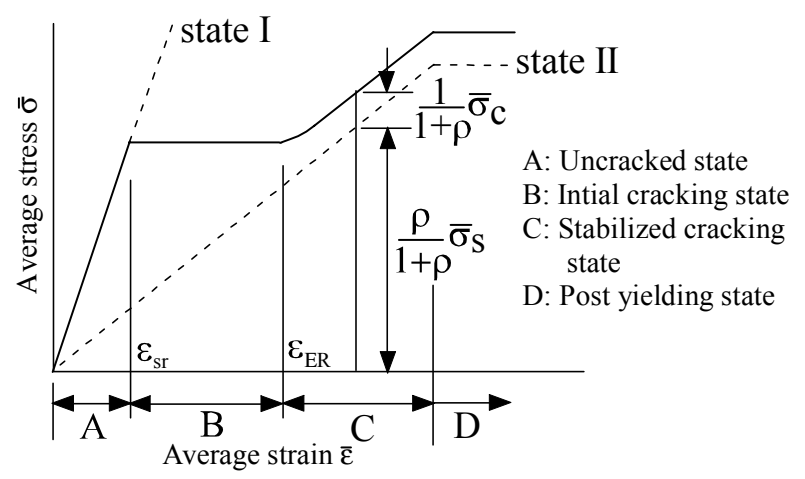

(a) Average stress-strain curves

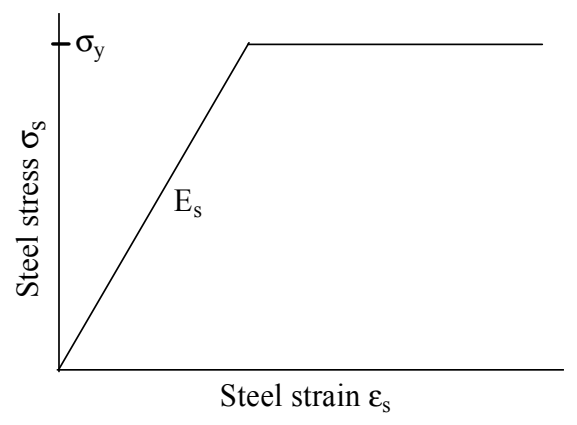

(b) stress-strain curve for steel

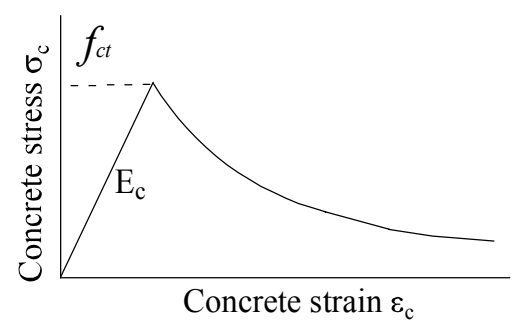

(c) stress-strain curve for concrete

Fig.3 Schematic figure for Stress-strain curves of RC member in tension. 
slip as those used by Hanswille ${ }^{2)}$. Hence, first we will introduce those equations briefly.

\section{(a) Constitutive model and bond-slip differential equation}

Consider a reinforced concrete member subjected to axial tensile force. When the stress attains the tensile strength of concrete, the first crack appears and the relative slip between steel reinforcement and surrounding concrete is produced. The following constitutive relation between the bond stress $\tau_{v}$ and the slip $v$ is used in Hanswille's theory

$$
\tau_{v}(x)=A f_{c w} v^{N}(x)
$$

where $A$ and $N$ are constants and $f_{c w}$ denotes the cubic compressive strength of concrete, and $x$ is the longitudinal coordinate of the member. Note that $N$ is not a nondimensional parameter but dimensional one. If the unit of length is $\mathrm{cm}$, then Hanswille ${ }^{2)}$ reported that $A=0.58$ and $N=0.3$ are standard values for a deformed bar.

By considering equilibrium of the $\mathrm{RC}$ member, a differential equation for bond-slip ${ }^{2}$ is given by

$$
\frac{d^{2} v}{d x^{2}}=\frac{4 A f_{c w}}{\phi}\left(\frac{1+n \rho}{E_{s}}\right) v^{N}(x)
$$

where $n=$ modular ratio.

Boundary conditions for the differential Eq.(7) depend on the magnitude of the applied tensile force and a state of cracking. After first cracking of concrete, further increase of the axial force increases the number of cracks and accordingly deformation due to cracking, and thus spacing between adjacent cracks reduces. Hence the boundary condition can be classified into two categories depending on two stages of cracking shown in Fig.4.

In the initial cracking stage, there is the state I region between two adjacent cracks. Since there is no relative slip in the state-I region, there is no interaction between two adjacent cracks. On the other hand, in the stabilized cracking stage, the bond slip regions of two adjacent cracks overlap each other. Hence we have to consider effects of other cracks on the boundary condition. In the following subsections, expressions of the crack width $w$ for both crack stages are listed. Each crack width expression can be derived from a corresponding particular solution of differential Eq.(7) with $w=2 v$ at the crack position.

\section{b) Initial cracking stage}

As shown in Fig.4(a), the concrete stress in State I region between two adjacent cracks attains to the concrete tensile strength $f_{c t}$ in the initial cracking stage. The crack width in the initial cracking stage $w_{R}$ is given by ${ }^{2)}$

$$
w_{R}=2\left[\frac{1+N}{A f_{c w}} \frac{\phi}{8} \frac{\Delta \sigma_{s r}}{E_{s}}\left(\sigma_{s r}-E_{s} \varepsilon_{0}\right)\right]^{\frac{1}{1+N}}
$$

for $\varepsilon_{s r}<\bar{\varepsilon}<\varepsilon_{E R}$ with

$$
\begin{gathered}
\sigma_{s r}=f_{c t} \frac{1+n \rho}{\rho}+\varepsilon_{0} E_{s} \\
\Delta \sigma_{s r}=\frac{f_{c t}}{\rho}
\end{gathered}
$$

where $\varepsilon_{0}$ denotes the strain of concrete due to shrinkage (contraction is negative).

Note that Hanswille considers the possibility of stress drop due to cracking in the initial cracking stage and proposes an expression of crack width when the applied stress is less than that in the first cracking as well. In the present FE analysis, however, we assume a constant stress state in the initial cracking stage as shown in Fig.4(a). Accordingly, we adopt Eq.(8), which is the crack width expression in the first cracking.

It should be also noted that $L_{E R}$ in Fig.4(a) is called the transmission length, and defined as the maximum length over which relative slip between steel and concrete occurs. The expression of the

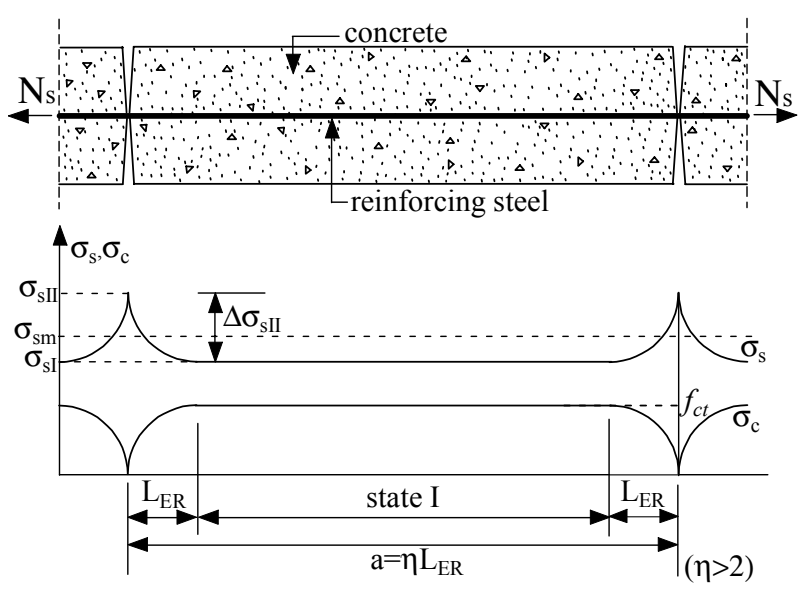

(a) Initial cracking stage
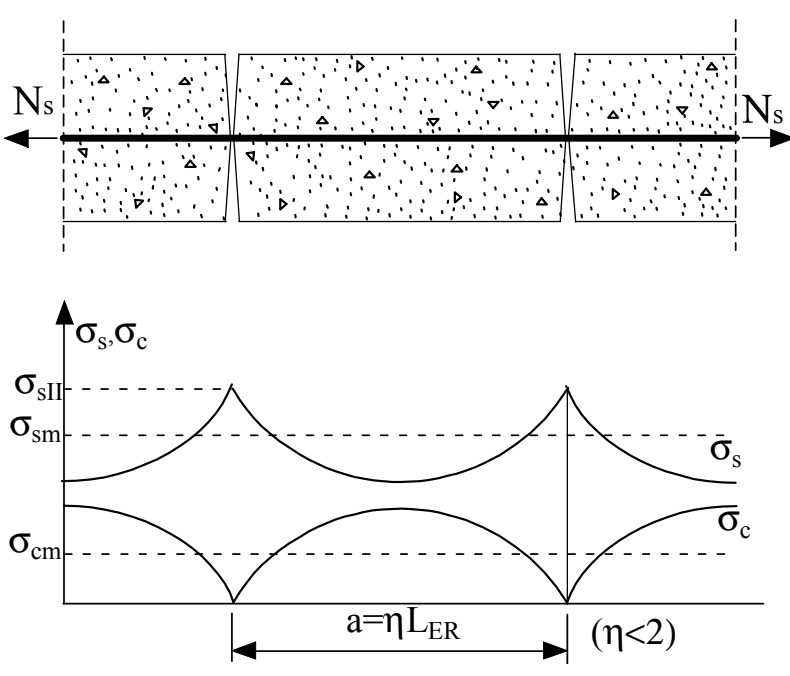

(b)Stabilized cracking stage

Fig.4 Stress distributions in cracked steel reinforced concrete member. 
transmission length is obtained by solving the differential Eq.(7) as

$$
L_{E R}=\frac{2}{1-N}\left[\left(\frac{E_{s}}{\sigma_{s r}-E_{s} \varepsilon_{0}}\right)^{N} \Delta \sigma_{s r} \frac{1+N}{A \beta_{w}} \frac{\phi}{8}\right]^{\frac{1}{1+N}}
$$

\section{c) Stabilized cracking stage}

In the stabilized cracking stage, the crack spacing $a$ is less than $2 L_{E R}$, and consequently two adjacent cracks interact each other, as shown in Fig.4(b). The crack width expression can be obtained from the differential Eq.(7) with a boundary condition in which the interaction effect is taken into account,

$$
w=w_{R} \alpha^{\frac{2}{1-N}}\left[1-\frac{\left(2 \alpha-\eta_{m}\right)^{2}}{\alpha-N\left(\alpha-\eta_{m}\right)} \frac{1-N}{4 \alpha}\right]
$$

where

$$
\alpha=\left(\frac{\sigma_{s I I}-\varepsilon_{0} E_{s}}{\sigma_{s r}-\varepsilon_{0} E_{s}}\right)^{\frac{1-N}{1+N}}
$$

and $\eta=a / L_{E R}$ is the nondimensional crack spacing. Hanswille ${ }^{2)}$ proposes the following expression as a mean value of $\eta_{m}$ on the basis of the statistical experimental data reported by König et al. ${ }^{17), 18)}$ :

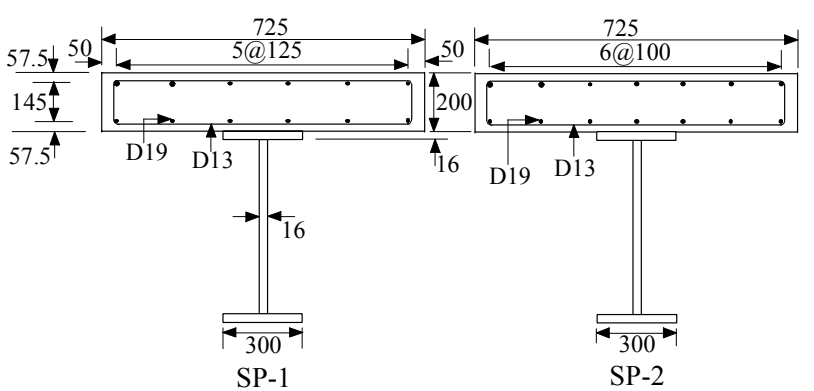

(a) Cross-section for SP-1 and SP-2

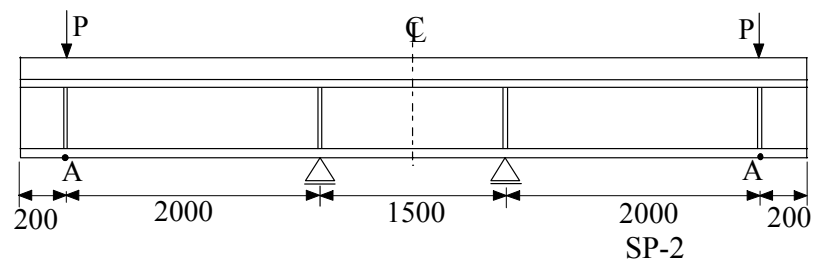

(b) Side view

Fig.5 Test specimen of composite girder.

Table 1 Details of reinforcements and studs in SP-1 and SP-2.

\begin{tabular}{lcl}
\hline Item & SP-1 & SP-2 \\
\hline $\begin{array}{l}\text { Longitudinal } \\
\text { inforcement }\end{array}$ & re-2×6-D19 & $2 \times 7-\mathrm{D} 19$ \\
$\begin{array}{l}\text { Reinforcement } \\
\text { ratio }\end{array}$ & $1.86 \%$ & $2.17 \%$ \\
$\begin{array}{l}\text { Transverse } \\
\text { forcement }\end{array}$ & rein-2×D13@150 & $2 \times \mathrm{D} 13 @ 150(200)^{*}$ \\
Stud & $2 \times \phi 19 @ 150$ & $2 \times \phi 19 @ 120$ \\
\hline
\end{tabular}

*) The transverse reinforcement pitch is changed from $150 \mathrm{~mm}$ to $200 \mathrm{~mm}$ at the span centre.

$$
\eta_{m}=\eta_{\max } / 1.1=\frac{2}{1.1}\left(\alpha^{*}-\beta^{*}\right)
$$

where

$$
\begin{aligned}
& \alpha^{*}=\left(\frac{\sigma_{s I I}-E_{s} \varepsilon_{0}}{\sigma_{s r}-E_{s} \varepsilon_{0}}\right)^{\frac{1-N}{1+N} \frac{2+N}{2}} \\
& \beta^{*}=\left(\frac{\sigma_{s I I}-E_{s} \varepsilon_{0}}{\sigma_{s r}-E_{s} \varepsilon_{0}}-1\right)^{\frac{1-N}{1+N} \frac{2+N}{2}}
\end{aligned}
$$

When evaluating the crack width by using Eq.(14), it is needed to know $\sigma_{s I I}$ from $\mathrm{FE}$ analysis. The relationship between $\sigma_{s I I}$ and the average stresses in $\mathrm{FE}$ analysis can be derived from the equilibrium condition, and we have

$$
\sigma_{s I I}=\bar{\sigma}_{s}+\frac{\bar{\sigma}_{c}}{\rho}
$$

The average strain derived from the bond-slip differential Eq.(8) is given by Hanswille, as follows:

$$
\begin{aligned}
& \varepsilon_{s m}=\frac{\sigma_{s I I}}{E_{s}} \times \\
& {\left[1-\frac{\Delta \sigma_{s I I}}{\sigma_{s I I}}\left[1-\frac{1-N}{\eta_{m}} \alpha\left[1-\left[1-\frac{1}{2} \frac{\eta_{m}}{\alpha}\right]^{\frac{2}{1-N}}\right]\right]\right]}
\end{aligned}
$$

From this average strain expression, we can specify the average stress-strain of a RC member, which is used in the FE analysis.

\section{COMPARISON WITH EXPERIMEN- TAL DATA}

\section{(1) Specimens and test setup}

To verify the proposed method for crack evaluation we compared the numerical results with experimental data ${ }^{14)}$, whose experimental tests were conducted at Nagaoka University of Technology. The cross-sectional dimensions, span and loading details for the two specimens (SP-1 and SP-2) are shown in Fig.5. In addition, details of reinforcements in the concrete slabs and studs are summarized in Table 1. The reinforcement ratio of SP-1 corresponds to normal continuous composite bridges, while that of SP-2 to heavily reinforced ones.

The two specimens are identical except for the reinforcement ratio, pitches of transverse reinforcement and stud arrangement. The material specification and material test results at a concrete age of 28 days are listed in Table 2.

$16 \pi$-gauges with a gauge length of $150 \mathrm{~mm}$ were attached on the top surface of the concrete slab in the central part of each specimen. These gauges were overlapped to ensure that all transverse crack 


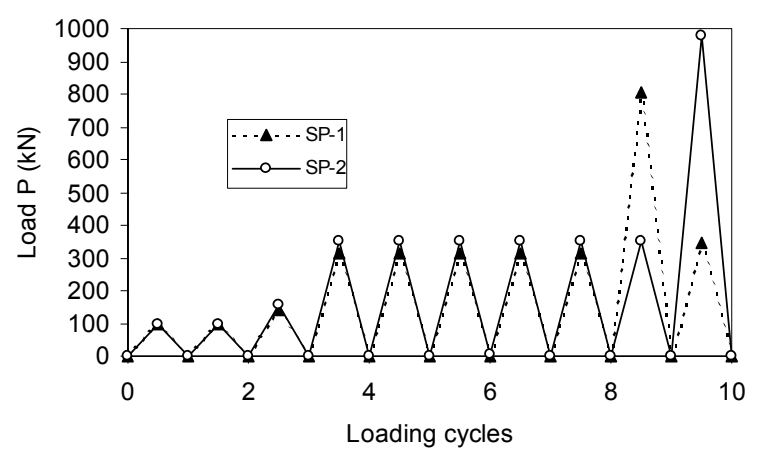

Fig.6 Load values applied in cyclic loading of specimens SP-1 and SP-2.

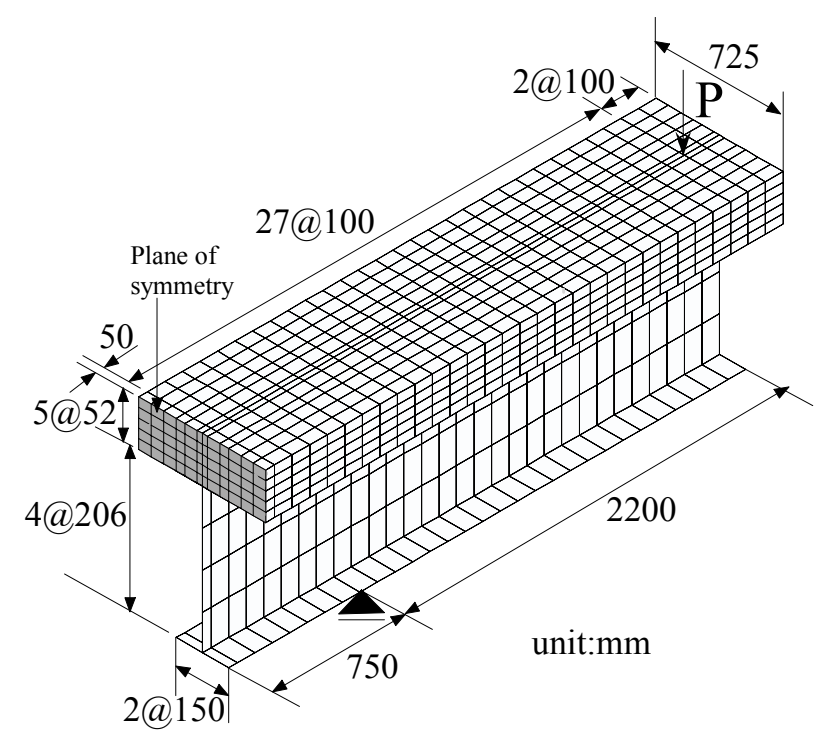

Fig.7 Mesh modelling used in the FE analysis.

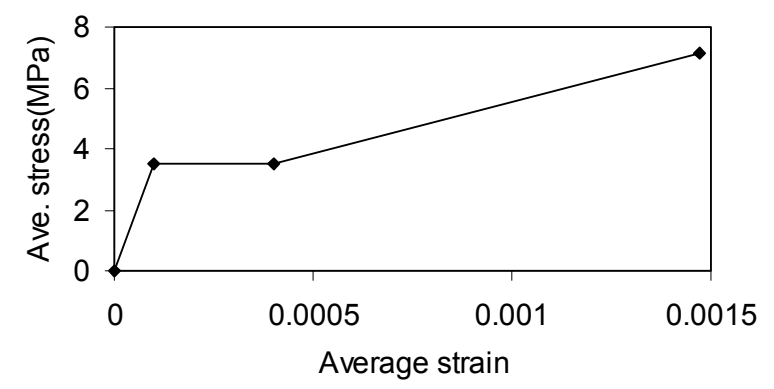

(a) Average stress-average strain relationship used in the FE analysis of SP-1.

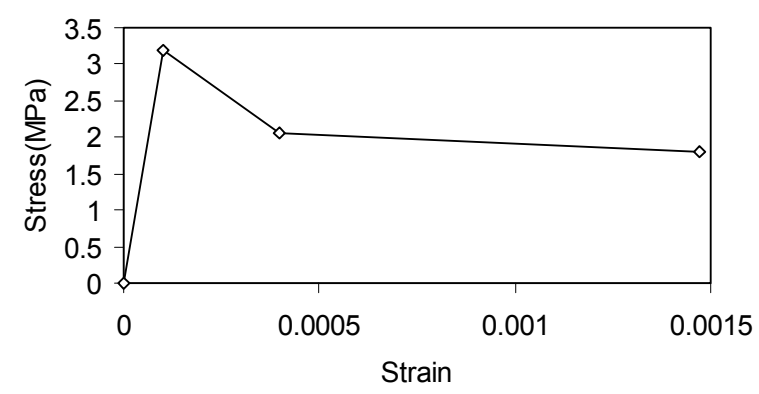

(b) Stress-strain relationship for concrete

Fig.8 Stress-strain relationship used in FE analysis of SP-1.
Table 2 Material specifications and material test results for specimens.

\begin{tabular}{ll}
\multicolumn{2}{c}{ (a) Material specifications } \\
\hline Steel & SS400A \\
Reinforcement & SD345 \\
Concrete & Normal portland cement \\
& (Design strength 40MPa) \\
\hline
\end{tabular}

(b) Material test results for concrete at 28 days

\begin{tabular}{ll}
\hline Compressive strength & $43.7 \mathrm{MPa}$ \\
Tensile strength & $3.19 \mathrm{MPa}$ \\
Young's modulus & $32.0 \mathrm{GPa}$ \\
Shrinkage strain & $-110 \mu^{*}$ \\
\hline at $20^{\circ} \mathrm{C}$ and a relative humidity of $60 \%$ with a rein- \\
rcement ratio of $1.8 \%$
\end{tabular}

Table 3 Material parameters used in FE analysis.

\begin{tabular}{|c|c|c|c|}
\hline $\begin{array}{l}\text { Material pa- } \\
\text { rameter }\end{array}$ & Concrete & $\begin{array}{l}\text { Reinforce- } \\
\text { ment }\end{array}$ & $\begin{array}{l}\text { Steel } \\
\text { Girder }\end{array}$ \\
\hline $\begin{array}{l}\text { Young's } \\
\text { modulus (GPa) }\end{array}$ & 30 & 200 & 200 \\
\hline Poison's ratio & 0.167 & 0.3 & 0.3 \\
\hline Density $\left(\mathrm{kg} / \mathrm{m}^{3}\right)$ & 2346 & 7857 & 7857 \\
\hline $\begin{array}{l}\text { Yield stress } \\
(\mathrm{MPa})\end{array}$ & ---- & 294 & 245 \\
\hline $\begin{array}{l}\text { Tensile strength } \\
(\mathrm{MPa})\end{array}$ & 3.18 & ----- & ----- \\
\hline $\begin{array}{l}\text { Compressive } \\
\text { strength }(\mathrm{MPa})\end{array}$ & 43.7 & ----- & ----- \\
\hline $\begin{array}{l}\text { Shear retention } \\
\text { factor }\end{array}$ & 0.25 & ---- & ---- \\
\hline Shrinkage strain & $-110 \times 10^{-6}$ & ----- & ------ \\
\hline
\end{tabular}

widths could be measured. The applied load $\mathrm{P}$ and the vertical displacements at point $\mathrm{A}$ in Fig.5(b) are measured with load cells and linear variable differential transformers (LVDTs), respectively. The load $P$ was applied in a cyclic way as shown in Fig.6. The loading tests for SP-1 and SP-2 were carried out at 36 and 59 days respectively after concrete casting.

\section{(2) FE modelling}

FE analysis employing the smeared fixed crack model was carried out for the composite beam specimens used in the experiment. The FE mesh used in the analysis is shown in Fig.7. Due to symmetry, only half of each specimen was analysed. The steel girder and concrete slab were modelled with four-node isoparametric shell elements and eight-node solid ones, respectively. The longitudinal reinforcement was modelled with embedded bar elements as explained before, while the transverse reinforcement was neglected in the analysis.

Fig.8(a) shows the average stress-strain relation of the RC slab for SP-1, which is obtained from Eq.(17) with $N=0.3$. This stress-strain relationship is decomposed into that for concrete (Fig.8(b)) and that for reinforcement steel in accordance with Eq.(5). These decomposed stress-strain relationships were used as input data in the FE analysis. Other 
input parameters for the analysis are listed in Table 3. FE analysis was carried out by using FE program DIANA $^{19)}$.

After cracking, concrete is modelled as an anisotropic material. The stiffness in the direction normal to the crack surface is evaluated in accordance with the stress-strain relationship shown in Fig.8(b), while that in the parallel direction retains the intact one. The decrease of the shear force transfer capability across the crack is taken into account by introducing the shear retention factor $\xi(0<\xi<1)$. In the present analysis, a constant reduced shear modulus $\xi G$ is assigned to cracked concrete, where $G$ is the shear modulus of the intact concrete. It is known that the shear force transfer capability, and accordingly the shear retention factor, decrease with increasing crack width ${ }^{20)}$. This type of modelling is essential for cracking under tension and shear loading. In the present problem, however, cracking is dominated by tension loading, and shear loading after cracking is not dominant. Therefore the constant shear retention model was used in the current analysis. The constant shear retention model was used by many researchers, and different values of the shear retention factor were adopted ${ }^{21,}$ 22), 23). A shear retention factor of $\xi=0.25$ was used by Hsuan and Schnobrich ${ }^{24)}$ and Crisfield and Wills ${ }^{25)}$. In addition, deterioration due to cyclic loading is neglected in the analysis.

It should be noted that nonlinear FE analysis with tension softening stress-strain relations, such as Fig.8(b), are frequently criticized for meshdependency and pathological localization of their numerical results. However, the present numerical results are confirmed not to depend on their mesh size. This is due to the embedded reinforcement, whose stiffness is superimposed on mother concrete elements. Thus, the total stiffness is not tension softening but hardening.

\section{(3) Load-displacement relationship}

Comparisons of the vertical displacements obtained from the FE analysis with the experimental results are presented in Fig.9. The experimental data plotted in Fig.9 are the average displacements at two points A in Fig.5(b). In Fig.9, the load-displacement curves based on the linear elastic analysis assuming State I are also plotted for comparison. Although the analytical displacements are smaller than the experimental ones for both specimens, the agreement between the numerical results and the experimental data is fairly good, especially for SP-2. In Fig.9(b), the two nonlinear FEM results are plotted as referred to as "without stud" and "with stud". These legends mean difference in modelling shear studs. This aspect will be discussed in a subsequent section.
One reason for this underestimation of deflection is overestimation of the tension stiffening effect in the FE analysis. In the FE analysis, the tension stiffening effect is taken into account by means of the average stress-strain relation, for example, shown in Fig.8 for SP-1. In the average stress-strain relation, $\beta$ defined by

$$
\beta=\frac{\varepsilon_{s I I}-\varepsilon_{s m}}{\varepsilon_{s r I I}-\varepsilon_{s I}} \quad(0 \leq \beta \leq 1)
$$

expresses the magnitude of the tension stiffening effect. For the present numerical analysis, $\beta$ values are ranging from 0.56 to 0.62 . In the meanwhile, CEB/FIP-90 specifies $\beta=0.4$ for short-term loading, and $\beta=0.25$ for long-term or repeated loading. Hence, it seems that the used average stress-strain relation obtained from Eq.(17) is not suitable for cyclic loading employed in the present experiments.

\section{(4) Crack width}

Using the proposed method, the crack widths were calculated at different load levels. In this calculation,

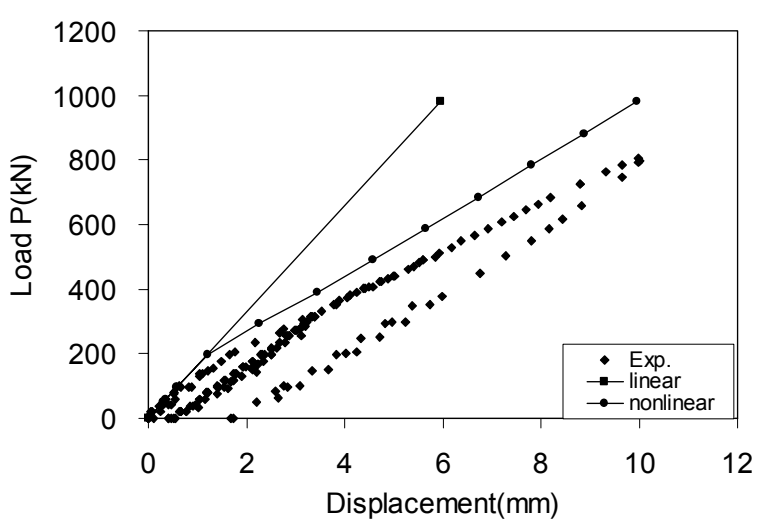

(a) $\mathrm{SP}-1$

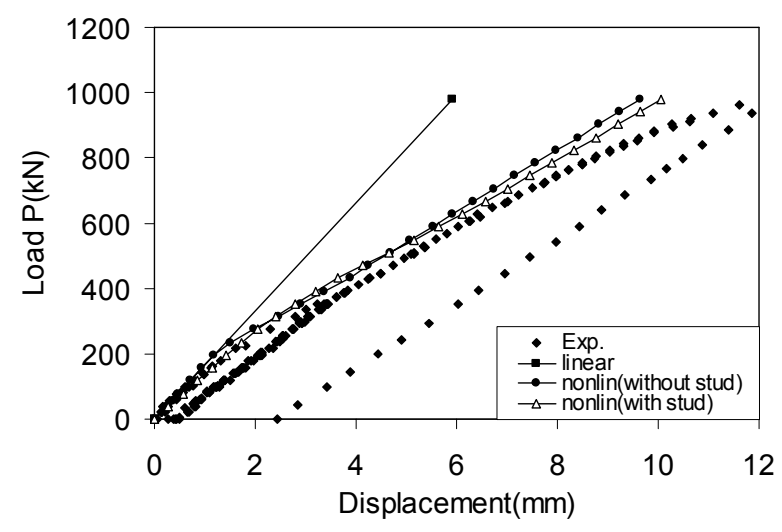

(b) SP-2

Fig.9 Comparison of load-displacement curves between experimental data and numerical results. 


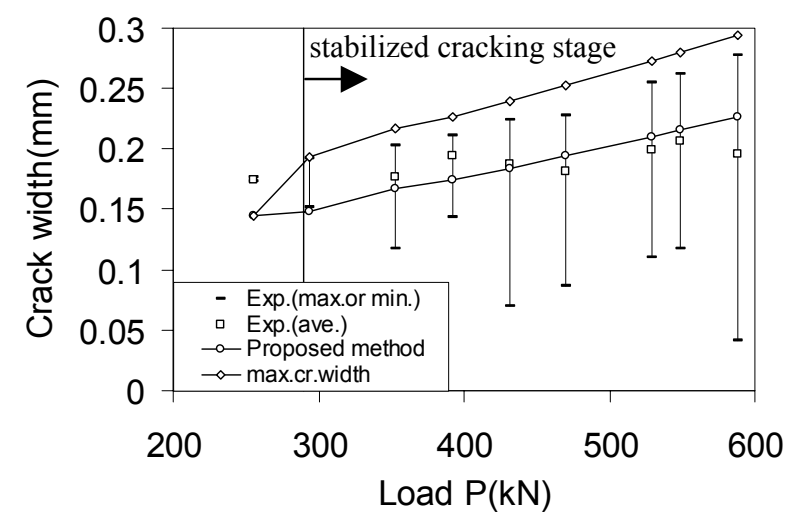

(a) SP-1

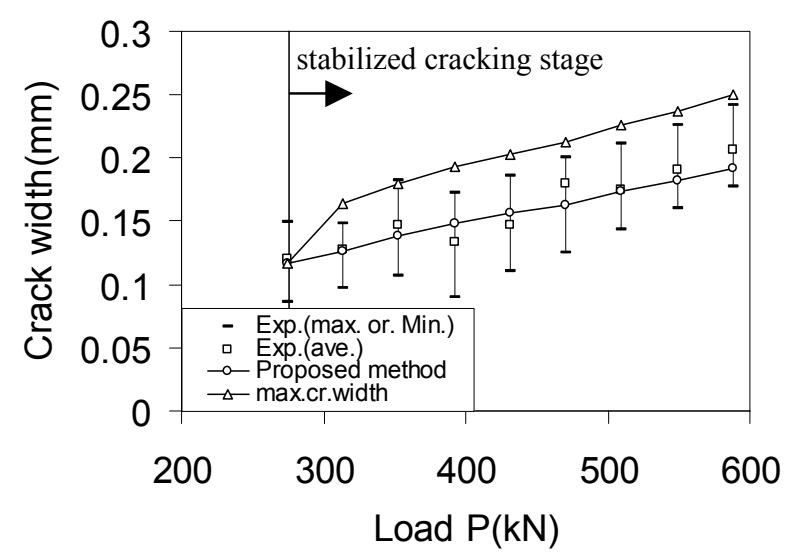

(b) SP-2

Fig.10 Comparison of crack width from proposed method with experimental data.

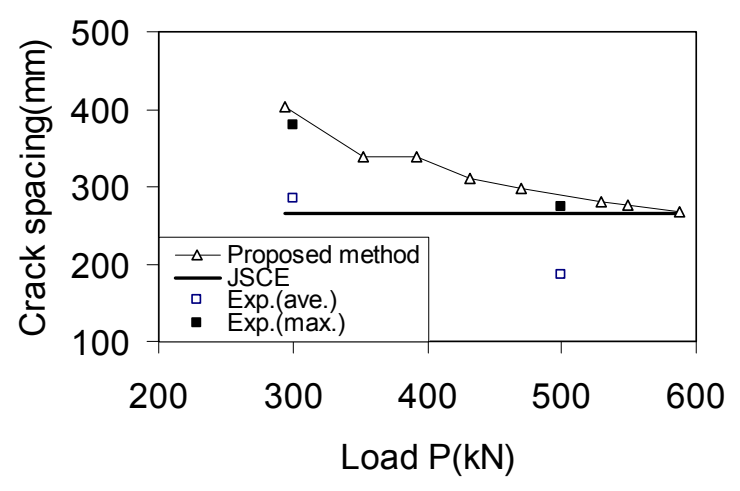

(a) SP-1

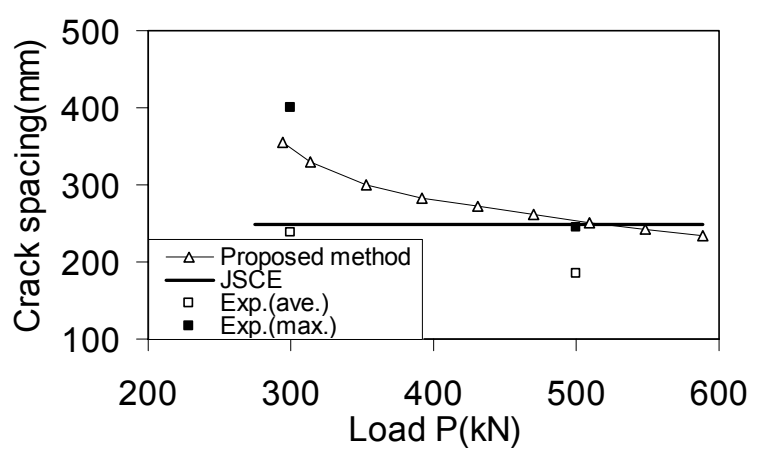

(b) SP-2

Fig.11 Comparison of crack spacing from proposed method with experimental data. the bond-slip parameters $A=0.58$ and $N=0.3$ in Eq.(12) were used; and the cubic concrete strength $f_{c w}$ was converted to the cylindrical one $f_{c m}$ in accordance with $f_{c m}=0.83 f_{c w}{ }^{26)}$.

Fig.10 shows comparisons between the experimental crack widths and the numerical ones. In this figure, an average crack width as well as the maximum and minimum crack widths within the constant bending moment region in the central part of each specimen are plotted. The average crack width is calculated from crack widths measured from the $\pi$ gauges through which cracks run. The number of cracks within the gauge length of each $\pi$-gauge is counted based on visual inspection. The experimental crack widths are considerably scattered in SP-1, while less scattered in SP-2. For SP-1, the numerical results are in good agreement with the average crack width, when $\mathrm{P}>500 \mathrm{kN}$. However, when $\mathrm{P}<500 \mathrm{kN}$, the numerical results are smaller than the average experimental data. On the other hand, for SP-2, the numerical results are in good agreement with the averaged experimental data over all the range of the applied load.

As shown in the previous chapter, the proposed method is intended to predict the maximum crack width in the initial cracking state and the average crack width in the stabilized cracking state. From an engineering point of view, however, it is more important to predict the maximum crack width than the averaged one. Hence, for the stabilized cracking state it is necessary to convert the average crack width obtained from the proposed method into the maximum one.

Leonhart ${ }^{27)}$ reported that the ratio of the maximum crack width to the averaged one in tensile RC members is 1.3 on the basis of his experimental data. The maximum crack widths converted by using this ratio are also plotted in Fig.10. The converted results are in good agreement with the experimental results.

\section{(5) Crack spacing and crack pattern}

Fig.11 compares the proposed model prediction for the crack spacing with the experimental results as well as the crack spacing prediction based on JSCE code ${ }^{5)}$. For experimental results, both average and maximum crack spacing are plotted, while the crack spacing obtained from the proposed method corresponds to the maximum value evaluated from the maximum non-dimensional crack spacing $\eta_{\max }$ in Eq.(14).

The maximum crack spacing obtained from the proposed method is in good agreement with the experimental results in the wide range of the stabilized cracking state. On the other hand, the prediction equation for crack spacing in JSCE code seems to be valid only in the end of the stabilized cracking state. 


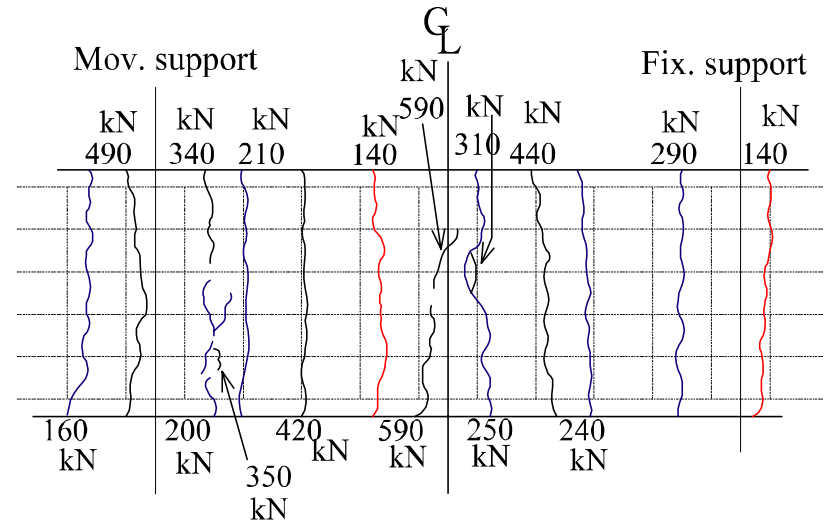

SP-1

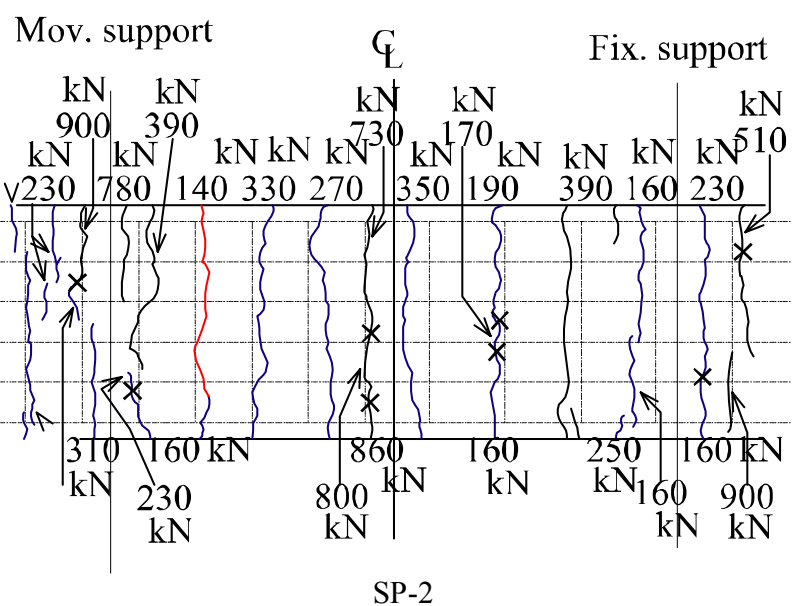

Fig.12 Top view of concrete deck showing crack pattern in test specimens.

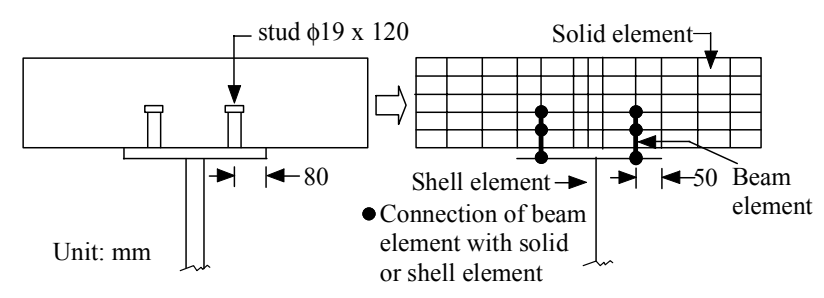

Fig.13 Modelling of studs for FE analysis.

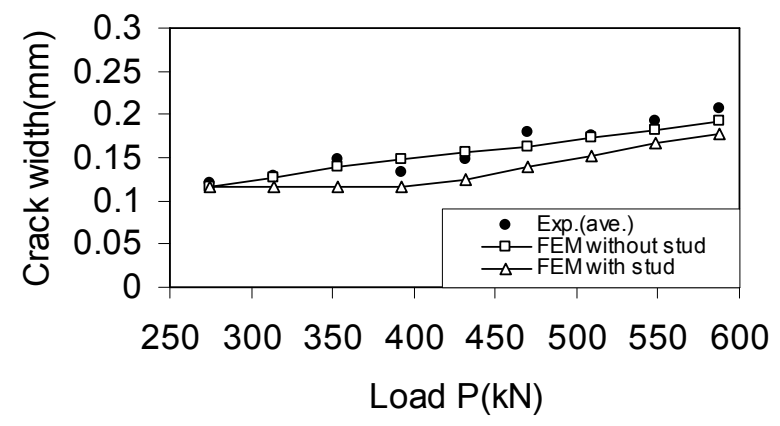

Fig.14 Effect of FE modelling of shear studs on crack width evaluation.

This is essentially due to that the JSCE's equation was deduced from experimental crack spacing data in the stabilized cracking ${ }^{28)}$.
Navarro ${ }^{29)}$ reported that cracks appear at positions of transverse reinforcement bars and consequently that the crack spacing equals the pitch of transverse reinforcement bars. To confirm this argument, crack maps together with positions of reinforcement bars for both SP-1 and SP-2 are illustrated in Fig.12.

Although the crack positions appear to be affected by the transverse reinforcement positions, some cracks run through between two adjacent reinforcement bars. Consequently, the average crack spacing reported in the present experiment does not coincide with the pitch of transverse reinforcement bars.

\section{(6) Effect of studs modelling}

So far, perfect bonding between the bottom of the concrete slab and the top of the upper flange plate has been assumed in the FE analysis. In this subsection, we consider the effect of shear stud deformation on cracking. To this end, the specimen SP-2 was also analysed employing beam elements that model shear studs explicitly as shown in Fig.13. In Fig.9(b), the load-displacement curve referred to as "with stud" is the FEM result employing the shear stud model in Fig.13, while that as "without stud" is from previous model. It can be seen from Fig.9(b) that explicit modelling of shear studs makes only a very slight improvement in the load-displacement relationship. Fig.14 compares the crack width obtained from the stud model with that from the perfect-bonding model. From the results of Fig.14, we conclude that the FE modelling of composite bridge without considering modelling of shear studs is appropriate in our proposed method of crack width evaluation.

\section{CONCLUDING REMARKS}

(1) The applicability of the effective width formula in Japanese Specifications for Highway Bridges (JSHB) to crack width evaluation for continuous composite bridges was examined through comparison with a wide concrete $\operatorname{deck}^{7}$. The crack width evaluated from Eq.(1) with the JSHB's effective width formula is less than the experimental maximum crack width. Hence, it seems that the direct application of JSHB's effective width formula to crack width evaluation leads to underestimation of the maximum crack width.

(2) A numerical procedure for evaluating crack width in continuous composite bridges has been proposed. The procedure is combination of $3 \mathrm{D} \mathrm{FE}$ smeared crack analysis and a bond-slip differential equation. The averaged behaviour including cracking in concrete is analysed with the FE analysis, and then the crack width is calculated from the averaged behaviour by using the bond-slip differential equa- 
tion. Since 3D FE analysis is employed in the proposed procedure, the variation of the crack width in the transverse direction due to shear-lag effect is evaluated directly. The crack width obtained from the proposed procedure was compared with experimental data. It was found that the obtained mean crack widths in the stabilized cracking state are in good agreement with the experimental mean crack width.

(3) Since the maximum crack width is more important than a mean crack width from a durability point of view, the mean crack widths calculated from the proposed procedure were converted into the maximum one based on statistical data reported by Leonhart ${ }^{27)}$. It was found that the converted maximum crack width, which is calculated with a max./mean crack width ratio of 1.3 , reasonably agrees with the maximum experimental crack width.

(4) The proposed procedure can be used in parametric studies to propose an effective width formula for the crack width evaluation. The effective width formula for crack width evaluation in continuous composite bridges is of future interest.

ACKNOWLEDGMENT: We would like to thank Komai Tekko Inc. for offering the composite girder specimens used in the reported experiments.

\section{REFERENCES}

1) Eurocode 4: Design of Composite Steel and Concrete Structures, Part 2, Bridges 1, Draft, 1996.

2) Hanswille, G.: Zur Rißbreitenbeschränkung bei Verbundträgern, Technisch-Weissenschaftliche Mitteilungen, Institut für Konstruktiven Ingenieurbau Ruhr-Universität Bochum, Mittelilung Nr. 86-1, 1986.

3) Expressway Technical Center: Design and construction manual for continuous composite 2-I girder bridges with prestressed concrete slab, 2002 (in Japanese).

4) Japanese Association of Steel Bridge Construction: Design example and commentary on 2-I girder continuous composite girder bridges with prestress concrete slab, 2001 (in Japanese).

5) Committee of Concrete: Standard specifications for con crete structures [Design], JSCE, 1998 (in Japanese).

6) Japan Road Association: Specifications for Highway Bridges, Part II (Steel bridges), 2002.

7) Shito, K., Kamihigashi, Y., Nagatani, T., Kasugai, T. and Sasaki, Y.: Fatigue test using a full-scale model of PC slab at a part of intermediate support for steel-concrete continu ous composite girders, Journal of Structural Engineering, JSCE, Vol. 46A, pp. 1535-1546, 2000 (in Japanese).

8) Sedlacek, G. and Bild, S.: A simplified method for the de termination of the effective width due to shear lag effects, Journal of Constructional Steel Research, Vol. 24, pp. 155182, 1993.

9) Song, Q. and Scordelis, A. C.: Shear-lag analysis of T-, I, and box beams, Journal of Structural Engineering, ASCE, Vol. 116, No. 5, pp. 1290-1305, 1990.
10) Song, Q. and Scordelis, A. C.: Formulas for shear-lag effect of T-, I-, and box beams, Journal of Structural Engineering, ASCE, Vol. 116, No. 5, pp. 1306-1318, 1990.

11) Kristek, V., Evans, H. R. and Ahmad, M. K. H.: A shear lag analysis for composite box girders, Journal of Constructional Steel Research, Vol. 16, pp. 1-21, 1990.

12) Evans, H. R., Ahmad, M. K. H. and Kristek, V.: Shear lag in composite box girders of complex cross-sections, Journal of Constructional Steel Research, Vol. 24, pp. 183204, 1993.

13) Amadio, C. and Fragiacomo, M.: Effective width evaluation for steel-concrete composite beams, Journal of constructional Steel Research, Vol.58, No. 3, pp. 373-388,2002.

14) Nagao, T.: Study on cracking in composite girders under negative bending moment, Master thesis, Nagaoka University of Technology, 2001 (in Japanese).

15) Ohgaki, K., Yabe, J., Nakazono, A., Nakamura, H., and Nagai, M.: Rational design and construction methods of a continuous composite two-I-girder bridge with PC slabs, Journal of Construction Management and Engineering, JSCE, Vol.679, No.51, pp.65-80, 2001 (in Japanese).

16) Rots, J. G. and Blaauwendraad, J.: Crack models for concrete: discrete or smeared? Fixed, multidirectional or rotating?, Heron, Vol.34, No. 1, pp. 1-59, 1989.

17) König, G. and Tue, N.: Crack width control for concrete constructions, Darmstadt Concrete, Vol. 7, pp. 231-245, 1999.

18) Tue, N. and König, G.: Calculating the mean bond and steel stress in reinforced and prestressed concrete members, Darmstadt Concrete, Vol. 6, pp. 77-86, 1991.

19) TNO Building and Construction Research: DIANA User's manual: Release 7.2, Delft, The Netherlands, 1998.

20) Cedolin, L. and Poli, S. D.: Finite element studies of shearcritical R/C beams, Journal of Engineering Mechanics, ASCE, Vol. 103, No. EM3, pp. 395-410, 1977.

21) Razaqpur, A. G. and Nofal, M.: Analytical modeling of nonlinear behaviour of composite bridges, Journal of Structural Engineering, ASCE, Vol. 116, No. 6, pp.17151733,1990

22) Wegmuller, A. W.: Overload behaviour of composite steelconcrete bridges, Journal of the Structural Division, ASCE, Vol. 103, No. ST9, pp. 1799-1819, 1977.

23) Rots, J. G. and Borst, R. D.: Analysis of mixed mode fracture in concrete, Journal of Engineering Mechanics, Vol. 113, No. 11, pp. 1739-1758, 1987.

24) Hsuan-The, $\mathrm{H}$ and Schnobrich, W. C.: Nonlinear analysis of cracked reinforced concrete, ACI Structural Journal, Vol.87, No. 2, pp. 199-207, 1990.

25) Crisfield, M. A. and Wills, J.: Analysis of R/C panels using different concrete models, Journal of Engineering Mechanics, ASCE, Vol. 115, No. 3, pp. 578-597, 1989.

26) Comite Euro-International du Beton: CEB-FIP Model Code 1978.

27) Leonhart, F.: Vorlesungen Über Massivbau, Vol.4, Springer-Verlag, 1978.

28) Kakuta, Y.: Maximum crack width of reinforced concrete, Concrete Journal, Vol. 8, No. 9, pp. 1-10, 1970 (in Japanese).

29) Navarro, M. G.: Concrete cracking in the deck slabs of steel-concrete composite bridges, Ph.D. Thesis no. 2268, Presentee au Departement de Genie Civil, Ecole Polytechnique Federale de Lausanne, Pour L'obtention du Grade de Docteur es Sciences Techniques, Lausanne, EPFL, 2000.

(Received October 30, 2002) 